\title{
Social media, past alcohol use, and the desire to drink
}

Jonathan K. Noel, PhD, MPH*

*Johnson \& Wales University, Department of Health Science, 8 Abbott Park Place, Providence, RI, USA 02903 . Tel.: +1 401598 5159; fax: +1 401598 4834. E-mail address: jknoel@hotmail.com

\begin{abstract}
Past alcohol use is positively associated with the desire to drink after exposure to social media alcohol ads. The current study sought to determine if this relationship was moderated by the user engagement values or user-generated comments (UGCs) that appear alongside the ads. An analysis of data collected for a mixed factorial experiment was conducted. Alcohol use was measured using the Alcohol Use Disorder Identification Test (AUDIT). The desire to drink among participants $(n=118)$ was measured after each of four Facebook beer ad exposures. Main and interactive effects were assessed using generalized linear mixed modeling, and models were adjusted for demographics and Facebook involvement. There was a significant interaction between AUDIT scores and UGCs $(\mathrm{p}=0.029)$. The desire to drink was significantly greater among higher-risk drinkers compared to low-risk drinkers ( $p^{\prime} s<0.001$ to $p=0.029$ ). Pro-drinking UGCs increased the desire to drink but only among low-risk drinkers $(\mathrm{p}<0.001)$. User engagement values had no effect. Regulating the content of social media alcohol ads may protect higher-risk drinkers. Regulating UGCs associated with social media alcohol ads may protect low-risk drinkers.
\end{abstract}

Keywords: alcohol; social media; user engagement; user-generated comments; marketing 


\section{Introduction}

\section{Response to Alcohol Cues}

Substantial research demonstrates that alcohol-related cues (e.g. a glass of beer) elicit multiple physiological and psychological responses important to future alcohol use and the addiction process (Bordnick et al., 2008; Eddie et al., 2013; Lee et al., 2008; Reid, Flammino, Starosta, Palamar, \& Franck, 2006). For example, among alcohol dependent patients recruited from a treatment program, alcohol cues significantly increased alcohol craving, desire to drink, alcohol-like highs, positive drinking expectancies, and alcohol-like withdrawal in a laboratory setting (Reid et al., 2006). Individuals with alcohol dependence have reported high levels of craving after exposure to alcohol cues when completing a virtual reality coping skills training program (Lee et al., 2008), and subjective craving for alcohol increased in a sample of nontreatment seeking individuals with alcohol use disorders after exposure to alcohol cues through a virtual reality program (Bordnick et al., 2008). Greater subjective arousal after cue exposure was also detected in a sample of college students mandated to undergo brief interventions for alcohol use (Eddie et al., 2013).

Binge drinking may be associated with higher reactivity to alcohol-related stimuli and lower reactivity to non-alcohol-related stimuli (Petit, Kornreich, Dan, Verbanck, \& Campanella, 2014), and greater alcohol cue reactivity may occur in non-dependent binge drinkers, with the effect more pronounced among men (Petit, Kornreich, Verbanck, \& Campanella, 2013). Moreover, positive affective stimuli associated with drinking occasions can stimulate craving in the absence of direct alcohol cues (Mason, Light, Escher, \& Drobes, 2008), and heavy alcohol users or those with symptoms of alcohol dependence may have greater reactions to images of 
drinking contexts, such as parties, than visualizations of a drink itself (Lee, Namkoong, Lee, An, \& Lee, 2006).

Physiologically, high craving heavy alcohol users have shown immediate heart deceleration and a significant increase in difficulty resisting a drink after exposure to alcohol pictures, indicating interest at an autonomic level along with pre-attentive processing and autonomic attentional focusing on the alcohol stimulus (Ingjaldsson, Thayer, \& Laberg, 2003a; Ingjaldsson, Thayer, \& Laberg, 2003b). Moreover, individuals with an alcohol use disorder may have difficulty disengaging from alcohol cues due to a deeper, semantic analysis of the cue that results in an inability to shift attention to a non-alcohol stimulus (Storkmark, Field, Hugdahl, \& Horowitz, 1997), and slower reaction times have been documented in heavy alcohol users after exposure to alcohol cues (Cox, Yeates, \& Regan, 1999).

\section{Digital Media}

With the rise of digital media, individuals are routinely exposed to alcohol cues through non-traditional platforms. Up to $96 \%$ of college students may view alcohol use by peers on social media (Erevik, Pallesen, Andreassen, Vedaa, \& Torsheim, 2018), and approximately $75 \%$ of these depictions may portray positive aspects of alcohol use (Erevik, Torsheim, Andreassen, Vedaa, \& Pallesen, 2017). Moreover, $40 \%$ of youth and $25 \%$ of adults may regularly view digital alcohol advertisements (Jernigan, Padon, Ross, \& Borzekowski, 2017), which can associate alcoholic beverages with adventure/sensation seeking, sports, and party atmospheres (Noel \& Babor, 2017).

Specific to social media platforms, such as Facebook, Instagram, or Twitter, there is substantial additional information surrounding each alcohol depiction. User engagement values are the total number of Likes, Shares, and Comments elicited by a social media post, and they may serve as a proxy for social reinforcement of a post's message (Boyle, Smith, Earle, \& LaBrie, 
2018). User-generated comments are comments that appear alongside a social media post and written by social media users in direct response to the post.

In general, the greater number of "Likes" a social media post receives, the more credible the post's message (Borah, \& Xiao, 2018). Greater perceived "Likes" of alcohol-related posts was predictive of peer approval for risky alcohol use among college non-drinkers (Boyle, Smith, Earle, \& LaBrie, 2018), and greater user engagement values associated with alcohol ads on Facebook was associated with increased drinking intentions (Alhabash, McAlister, Quilliam, Richards, \& Lou, 2015). Similarly, pro-drinking user-generated comments associated with beer advertisements on Facebook increased the desire to drink in a sample of young adults (Noel, \& Babor, 2018). Indeed, user engagement values and user-generated comments may explain, in part, the positive association between viewing alcohol-related material on social media and alcohol use (Hoffman, Pinkleton, Weintraub Austin, \& Reyes-Velázquez, 2014).

\section{Alcohol Advertising on Social Media}

Alcohol advertising has proliferated on social media platforms through the last two decades (Jernigan \& Rushman, 2014). For example, there were 100,000 subscriptions to 20 Indian and Australian alcohol brands YouTube channels by 2015 (Gupta, Lam, Pettigrew, \& Tait, 2018), and the brands Heineken, Budweiser, Smirnoff, Skol, and Johnnie Walker exceeded 12 million Likes on Facebook by the same year (Lobstein, Landon, Thornton, \& Jernigan, 2017). Heineken and Chivas Regal gained over 500,000 Likes over the Christmas-New Year's period in 2015-2016 alone.

Descriptive and thematic content analyses have been conducted on alcohol ads published on social media. Ads often include notifications of parties, concerts, and other events; feature celebrities; provide opportunities to download branded apps or widgets; and direct appeals for 
product purchases (Lobstein et al., 2017). A review of Instagram posts found product appeals and the physical benefits of alcohol as the most common with significant minorities focusing on camaraderie, individuality, personal achievement, and positive emotions (Barry et al., 2018). A similar review of Facebook posts identified adventure/sensation seeking and sports in a majority of posts (Noel \& Babor, 2017).

Currently, there are no federal regulations in the United States (U.S.) restricting alcohol advertising activities. Consequently, the U.S. alcohol industry has voluntarily agreed to restrict alcohol advertising through a self-regulatory system wherein the industry creates and enforces a specific set of rules (International Alliance for Responsible Drinking [IARD], 2011; IARD, 2014). These self-regulation codes contain several provisions intended to restrict the content, exposure, and access to social media alcohol ads. However, current evidence suggests poor compliance with these rules. Approximately $80 \%$ of social media ads may contain content that violates the codes (Noel \& Babor, 2017), and several studies have demonstrated that currently technology is insufficient to prevent minors from accessing such content (e.g. Barry et al., 2016; Barry et al., 2015; Jones, Thom, Davoren, \& Barrie, 2014).

\section{Study Purpose}

In light of past research demonstrating that heavy alcohol users react strongly to alcohol cues and recent research highlighting attributes of social media that may moderate the response to alcohol cues, the present study was conducted to determine if user engagement values or usergenerated comments moderate the relationship between alcohol use and the desire to drink after exposure to Facebook beer ads. It was hypothesized that user engagement values and usergenerated comments will have no effect on heavy alcohol users due to autonomic processing and 
focused attention on the alcohol cue (i.e. beer ad). Any effects of user engagement or usergenerated comments would be reserved for non-heavy alcohol users.

\section{Methods}

The present study analyzed data collected for a 2 (within) x 2 (between) x 2 (between) factorial experiment that was designed to determine if ad content, user engagement values, and/or user-generated comments (UGCs) were associated with the desire to drink after viewing four Facebook beer ads. Study participants were randomized to one of four between-subject study conditions: high user engagement/pro-drinking UGCs, high user engagement/anti-drinking UGCs, low user engagement/pro-drinking UGCs, and low user engagement/anti-drinking UGCs. The desire to drink was measured after each ad exposure. It was previously reported that alcohol ad content had no effect on the desire to drink (Noel, \& Babor, 2018), and as such, the effect of ad content was ignored during the present analysis.

\section{Participants}

A convenience sample of participants were recruited from Amazon's Mechanical Turk (AMT), an online platform that can produce representative samples of the U.S. population (Simons, \& Chabris, 2012). Participants were required to live in the U.S., be 21 to 24 years old, and have internet access. There were no exclusion criteria. Participant recruitment occurred in two stages. In stage one, a screening survey was posted on AMT. Individuals completing the screening survey $(n=1,759)$ were compensated $\$ 0.05$ through the AMT platform. Private invitations were sent to study eligible individuals $(n=200,11 \%)$. Among study eligible individuals, $60 \%(\mathrm{n}=120)$ agreed to participate and were reimbursed $\$ 10$ through AMT at study completion. All individuals who agreed to participate in the study completed the minimum study requirements $(100 \%)$. 


\section{Ad Selection}

Each participant viewed four Facebook beer ads that were previously evaluated for content (Noel \& Babor, 2017). Beer ads were selected due to their rapid proliferation on social media, and the ability of minors to access the brand's social media profiles. Ads were published by Bud Light $\left(\mathrm{n}_{\mathrm{ad}}=2\right)$ and Budweiser $\left(\mathrm{n}_{\mathrm{ad}}=2\right)$ within one month of the 2015 U.S. National Football League Super Bowl. Bud Light and Budweiser were selected because they were the official beer sponsors of the Super Bowl, and there was the potential for a large volume of ad exposure before, during, and after the event. The ads were purposefully selected based on their compliance with a selfregulated alcohol marketing code (i.e. two ads were compliant and two ads were non-compliant) and for content (i.e. each compliant ad was matched for content with a same brand non-compliant ad). The ads used in the study were published in Supplemental Figure 1 of Noel et al. (2018).

\section{User Engagement Values}

User engagement values were defined as the total number of Likes, Shares, and Comments elicited by a Facebook beer ad. Each ad was associated with a unique set of user engagement values. Real-world values were taken from a sample of Facebook Bud Light and Budweiser ads that were previously evaluated for content and regulatory compliance (Noel, \& Babor, 2017). Participants were randomized to view either high (e.g. "27k Likes", "11k Shares", “4.5k comments") or low, but non-zero, user engagement values (e.g. "216 Likes", "22 Shares", "12 Comments"). The wide discrepancy between the high and low values group was purposefully selected to elicit a large between-group difference. 


\section{User-Generated Comments (UGCs)}

UGCs were defined as comments published by non-brand affiliated Facebook users in direct response to the Facebook beer ad and that appeared directly below the ad. Each ad was associated with a unique set of UGCs. Each set consisted of two unique, real-world comments that were written by actual Facebook users in response to a previously evaluated Bud Light or Budweiser Facebook ad (Noel, \& Babor, 2017). Two comments were used to mimic the default number of comments that appear beneath a Facebook post, and comments were selected based on the results of a thematic content analysis (Noel, Babor, \& Grady, 2018). Participants were randomized to view either pro-drinking or anti-drinking UGCs. Within the pro-drinking UGC group, each ad was associated with one "positive consequences" comment (e.g. "Some call it a six pack I call it my support group") and one "past drinking" comment (e.g. "I done had so many of these tonight lol"). Within the anti-drinking UGC group, each ad was associated with one "negative consequences" comment (e.g. "I lost a friend behind your product. U guys suck") and one "abstinence/sobriety" comment (e.g. "i dont even drink or smoke ,cant say i miss this"). Comments were selected randomly from each thematic category.

\section{Desire to Drink}

The desire to drink was measured using one item (France et al., 2014). After each ad exposure, participants were asked if the ad would increase or decrease the desire to drink in an individual like them. Responses were captured on a 5-point Likert scale that ranged from definitely decrease (coded as 0) to definitely increase (coded as 4). The reference frame "an individual like them" was used to separate the issue from the participant and elicit a more reliable response (Bradburn, Sudman, \& Wansink, 2004). Four desire to drink measurements, one per ad, were recorded per participant. 


\section{Alcohol Use}

Past year alcohol use was measured using the Alcohol Use Disorder Identification Test (AUDIT) (Saunders, Aasland, Babor, de al Fuente, \& Grant, 1993). The AUDIT consisted of 10 questions that measured past year alcohol consumption, alcohol dependence symptoms, and harmful alcohol use $(\alpha=0.83)$. Possible AUDIT scores range from 0 to 40 with scores $\leq 7$ indicating abstinence or low risk drinking, scores from 8-15 indicating hazardous drinking, scores from 16-19 indicating harmful alcohol use, and scores $\geq 20$ indicating possible alcohol dependence (Babor, \& Robaina, 2016).

\section{Covariates}

Participants answered several demographic (i.e. age, sex, race, ethnicity, household income, marital status) and Facebook involvement questions. Facebook involvement was measured using a 29-item questionnaire based on the Technology Acceptance Model that was developed specifically for use with Facebook $(\alpha=0.93)$ (Rauniar, Rawaski, Yang, \& Johnson, 2014). This measure was included to control for familiarity, use, and trust of Facebook.

\section{Study Procedure}

The study was conducted online. Participants consented to participate through affirmation after reading a study description. Then, participants were randomized into one of the four experimental, between-subjects groups (i.e. high user engagement/pro-drinking UGCs, high user engagement/anti-drinking UGCs, low user engagement/pro-drinking UGCs, low user engagement/anti-drinking UGCs) and viewed the four experimental beer ads. A Latin Square design was implemented to ensure that each group viewed the ads in a unique order. After viewing each ad, participants completed a questionnaire that contained the desire to drink question. Once 
all ads were viewed and related questions answered, participants completed a questionnaire containing demographic, Facebook involvement, and AUDIT questions. The UConn Health Institutional Review Board approved this procedure as an exempt protocol.

\section{Statistical Analysis}

All continuous variables were considered normally distributed after an examination of their distributions for skewness and kurtosis. Differences in demographic variables across study groups were assessed using t-tests and chi-square analysis. Statistical significance of main and interactive effects of user engagement values, UGCs, and AUDIT scores were assessed using generalized linear mixed models (GLMM), which is an extension of general linear models that adjusts for correlated outcomes that originate from the same participant. The Akaike Information Criterion (AIC) and Bayesian Information Criterion (BIC) were used to assess relative model fit. Models with minimum AIC and BIC scores were preferred.

AUDIT scores were dichotomized to categorize participants as either abstinent/low-risk drinkers (i.e. scores $\leq 7$ ) or higher-risk drinkers (i.e. scores $>7$ ). Unadjusted and adjusted GLMM models were specified. The unadjusted model included user engagement values, UGCs, AUDIT category, and all interactions between these three variables (i.e. user-engagement x UGCs, user engagement x AUDIT category, UGCs x AUDIT category, user-engagement x UGCs x AUDIT category). User engagement, UGCs, and AUDIT categories were simple contrast coded, with high user engagement values, pro-drinking UGCs, and higher-risk drinkers coded as 1/2. Low user engagement values, anti-drinking UGCs, and abstinent/low-risk drinkers were coded as $-1 / 2$.

The adjusted model included age, sex, race, ethnicity, income, marital status, and Facebook involvement as covariates. Age, income, and Facebook involvement were considered continuous variables. Sex and ethnicity were dummy coded dichotomous variables where males and non- 
Hispanic were the reference categories. Due to lower AIC and BIC scores, the race variable was dichotomized into Caucasians and non-Caucasians, then dummy coded with Caucasians as the reference group. Using similar criteria, the marital status variable was specified as a dummy coded four level categorical variable (i.e. single, never married; married, domestic partnership, widowed, divorced), and divorced was the reference category.

Significant interactions that have not been previous explored were investigated by first identifying all possible groups created by the interacting variables. For example, a significant user engagement $\mathrm{x}$ UGC interaction would create four groups: high user engagement/pro-drinking UGCs, high user engagement/anti-drinking UGCs, low user engagement/pro-drinking UGCs, low user engagement/anti-drinking UGCs. New models were then specified using each new group as the reference group. For a 2-way interaction, the procedure would result in four additional GLMM models being specified.

Only participants with complete data were included in the analysis $(\mathrm{n}=118)$. All models were specified with a normal distribution and an identity link function. Statistical significance was set at $\alpha=0.05$. Statistical analysis was performed using SPSS Version 22.0 (Armonk, NY: IBM Corp.).

\section{Results}

Mean age was 22.7 years $(\mathrm{SD}=1.1)$; mean household income was approximately $\$ 40,000$ per year $(\mathrm{SD}=\$ 30,000)$, and mean Facebook involvement score was $82.2(\mathrm{SD}=16.5)$. Participants were predominantly Caucasian (67.8\%), non-Hispanic (86.4\%), and single, never married (89\%) (Table 1). A slight majority were male (51.7\%). Mean AUDIT score was 5.7 (SD $=5.9$ ) and $30 \%$ of participants were categorized as higher-risk drinkers (i.e. AUDIT score > 7) 
(Table 1). There were no significant differences in the demographic variables between study groups (p’s $>0.05)$.

\begin{tabular}{|c|c|c|c|}
\hline Variable & & Number & Percent (\%) \\
\hline \multicolumn{4}{|l|}{ Sex } \\
\hline & Male & 61 & 51.7 \\
\hline & Female & 57 & 48.3 \\
\hline
\end{tabular}

$\begin{array}{rcc}\text { American Indian/Native } & & \\ \text { Alaskan } & 2 & 1.7 \\ \text { Asian } & 15 & 12.7 \\ \text { Black } & 12 & 10.2 \\ \text { Caucasian } & 80 & 67.8 \\ \text { Other } & 3 & 2.5 \\ \text { Two or more races } & 6 & 5.1 \\ \text { Ethnicity } & & \\ \text { Non-Hispanic } & 102 & 86.4 \\ \text { Hispanic } & 16 & 13.6 \\ \text { Marital Status } \quad 105 & 89.0 \\ \text { Single, never married } & 105 & \\ \text { Married, domestic } & & 9.3 \\ \text { partnership } & 11 & 0.8 \\ \text { Widowed } & 1 & 0.8 \\ \text { AUDIT Category } \quad 1 & 70.3 \\ \text { Divorced, separated } & 1 & 29.7 \\ \text { Low Risk } & 83 & \\ \text { High risk } & 35 & \end{array}$

The AIC and BIC values of the unadjusted model were 1198.1 and 1214.5 , respectively. Slight improvement was noted in the adjusted model, where the AIC and BIC were 1197.0 and 1214.4, respectively. Therefore, the estimates of the adjusted model were interpreted. AUDIT category was positively associated with the desire to drink $(\mathrm{p}<0.001)$ (Table 2$)$. The user engagement by UGC interaction $(\mathrm{p}=0.049)$ and the UGC by AUDIT category interaction $(\mathrm{p}=$ 0.029) were also statistically significant. The main effects of user engagement and UGCs, along with the user engagement by AUDIT category and the user engagement by UGC by AUDIT category interactions were not statistically significant (p's $>0.05)$. 
Table 2. Unadjusted and adjusted results of the effect of user engagement values, UGCs, and AUDIT category on drinking intentions.

\begin{tabular}{|c|c|c|c|c|c|c|}
\hline \multirow[b]{2}{*}{ Variable } & \multicolumn{3}{|c|}{ Unadjusted } & \multicolumn{3}{|c|}{ Adjusted } \\
\hline & Estimate & $S E$ & $p$-value & Estimate & $S E$ & p-value \\
\hline User engagement & -0.09 & 0.09 & 0.309 & -0.13 & 0.09 & 0.142 \\
\hline User-generated comments & 0.14 & 0.09 & 0.098 & 0.16 & 0.09 & 0.071 \\
\hline AUDIT category & 0.51 & 0.09 & $<0.001$ & 0.46 & 0.09 & $<0.001$ \\
\hline User engagement by & & & & & & \\
\hline $\begin{array}{l}\text { User- generated comments } \\
\text { User engagement by }\end{array}$ & 0.39 & 0.17 & 0.025 & 0.35 & 0.18 & 0.049 \\
\hline $\begin{array}{l}\text { AUDIT category } \\
\text { User-generated comments by }\end{array}$ & 0.21 & 0.17 & 0.213 & 0.16 & 0.18 & 0.359 \\
\hline $\begin{array}{l}\text { AUDIT category } \\
\text { User engagement by }\end{array}$ & -0.41 & 0.17 & 0.019 & -0.39 & 0.18 & 0.029 \\
\hline User-generated comments by & & & & & & \\
\hline AUDIT category & -0.57 & 0.34 & 0.097 & -0.53 & 0.36 & 0.140 \\
\hline Age & 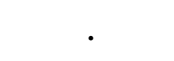 & . & & -0.05 & 0.04 & 0.203 \\
\hline Sex & & & & & & \\
\hline Female & . & . & & -0.27 & 0.08 & 0.001 \\
\hline Male & & . & & & . & - \\
\hline Non-Caucasian & & . & & 0.09 & 0.09 & 0.294 \\
\hline Caucasian & . & . & & 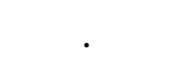 & . & . \\
\hline Ethnicity & . & . & & 0.19 & 0.12 & 0.107 \\
\hline Non-Hispanic & . & . & . & 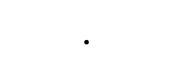 & . & . \\
\hline Marital status & & & & & & \\
\hline $\begin{array}{r}\text { Single, never married } \\
\text { Married, domestic }\end{array}$ & . & . & & 0.26 & 0.46 & 0.572 \\
\hline partnership & & $\cdot$ & & 0.17 & 0.48 & 0.720 \\
\hline Widowed & . & . & & -0.04 & 0.63 & 0.955 \\
\hline Divorced & . & 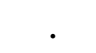 & & & & \\
\hline Income & & $\cdot$ & & 0.01 & 0.01 & 0.362 \\
\hline Facebook involvement & & . & & 0.01 & $<0.01$ & $<0.001$ \\
\hline
\end{tabular}

The UGC by AUDIT category interaction was investigated by first identifying all possible groups created from these two variables. The groups included: pro-drinking UGCs/high risk drinking, anti-drinking UGCs/high risk drinking, pro-drinking UGCs/low risk drinking, and antidrinking UGCs/low risk drinking. Four additional GLMM models were specified with each new group acting as the reference group in one of the models (Table 3). The desire to drink was greater 
among higher-risk drinkers regardless of the type of UGCs participants were exposed to (p's < 0.001 to $\mathrm{p}=0.029)$. Additionally, pro-drinking UGCs increased the desire to drink among lowrisk drinkers $(\mathrm{p}<0.001)$ but had no effect among higher-risk drinkers $(\mathrm{p}=0.989)$. The user engagement by UGC interaction within this dataset has been investigated elsewhere and the analyses were not duplicated here (Noel, \& Babor, 2018). Briefly, pro-drinking UGCs were associated with an increased desire to drink but only in the presence of high user engagement levels.

Table 3. Investigation of the user-generated comment by AUDIT category interaction.*

\begin{tabular}{lccc}
\hline Variable & Estimate & SE & p-value \\
\hline Model 1 & & & \\
Pro-Drinking UGCs/High risk drinking & 0.63 & 0.13 & $<0.001$ \\
Anti-Drinking UGCs/High risk drinking & 0.63 & 0.13 & $<0.001$ \\
$\quad$ Pro-Drinking UGCs/Low risk drinking & 0.35 & 0.09 & $<0.001$ \\
Anti-Drinking UGCs/Low risk drinking & $\cdot$ & $\cdot$ & $\cdot$ \\
Model 2 & & & \\
Pro-Drinking UGCs/High risk drinking & 0.28 & 0.12 & 0.025 \\
Anti-Drinking UGCs/High risk drinking & 0.27 & 0.13 & 0.029 \\
Pro-Drinking UGCs/Low risk drinking & $\cdot$ &. &. \\
Anti-Drinking UGCs/Low risk drinking & -0.35 & 0.09 & $<0.001$ \\
Model 3 & & & \\
Pro-Drinking UGCs/High risk drinking & 0.002 & 0.15 & 0.989 \\
Anti-Drinking UGCs/High risk drinking & $\cdot$ & $\cdot$ &. \\
Pro-Drinking UGCs/Low risk drinking & -0.27 & 0.13 & 0.029 \\
Anti-Drinking UGCs/Low risk drinking & -0.63 & 0.13 & $<0.001$ \\
Model 4 & & & \\
Pro-Drinking UGCs/High risk drinking &. &. &. \\
Anti-Drinking UGCs/High risk drinking & -0.002 & 0.15 & 0.989 \\
Pro-Drinking UGCs/Low risk drinking & -0.28 & 0.12 & 0.025 \\
Anti-Drinking UGCs/Low risk drinking & -0.63 & 0.13 & $<0.001$ \\
\hline
\end{tabular}

*All models adjusted for age, sex, race, ethnicity, marital status, income, Facebook involvement, user engagement value group, and the user engagement by UGC interaction 


\section{Discussion}

The findings support the study hypotheses in part and reject the hypotheses in part. Supportive findings include the suggestion that the desire to drink increases in higher-risk drinkers after exposure to a social media alcohol advertisement solely due to the ad itself. Moreover, prodrinking user-generated comments may increase the desire to drink among low-risk drinkers or those who are abstinent. However, the hypothesis that user engagement values would influence the desire to drink was not supported.

The increased desire to drink among high risk drinkers is consistent with previous research concluding that reactions to alcohol cues are stronger among moderate and heavy drinkers compared to non-drinkers or light drinkers (Bordnick et al., 2008; Eddie et al., 2013; Lee et al., 2008; Reid et al., 2006). The results are also consistent with the growing literature demonstrating that alcohol advertisements can elicit strong reactions, in addition to generic alcohol cues (e.g. a glass of beer). For instance, exposure to print alcohol ads significantly increased skin conductance in a sample of moderate drinking undergraduate students, indicating anticipation of the alcoholrelated stimuli (Cassisi et al., 1998). Viewing social media alcohol ads may also activate the reward pathways of the brain, which has been previously correlated with self-reported drinking behaviors (Courtney et al., 2018; de Sousa Fernandes Perna et al., 2017).

Furthermore, the lack of response among higher-risk drinkers to user-generated comments is consistent with research demonstrating that moderate and heavy alcohol users principally focus on the primary alcohol stimulus, in this case the alcohol ad, and typically ignore peripheral information (Ingjaldsson et al., 2003a; Ingjaldsson et al., 2003b). Previous research suggests that this effect may be greatest among youth and young adults. Greater attentional biases have been 
documented in underage college drinkers (Ramirez et al., 2015), and young adult binge drinkers may prioritize the processing of alcohol-related stimuli (Petit et al., 2012).

Conversely, the influence of user-generated comments among low-risk drinkers or those who were abstinent may suggest that the comments are viewed as reflective of peer behavior, and a stronger response towards increased alcohol consumption is warranted if group opinion is generally favorable to the ad message. The association between pro-drinking messages on social media and binge drinking intentions may be mediated by perceived injunctive norms (Yang \& Zhao, 2018), and others have postulated that reinforcement of social norms is an important motivational factor for writing online comments (Rost, Stagel, \& Frey, 2016). Indeed, social media may be an ideal outlet for those with such desires

\section{Implications}

Exposure to alcohol advertising moderately increases alcohol consumption (Anderson, de Bruijn, Angus, Gordon, \& Hastings, 2009; Jernigan, Noel, Landon, Thornton, \& Lobstein, 2017), and there have been several recent calls for greater regulation of alcohol marketing, with specific attention to alcohol marketing on social media platforms (Noel, \& Babor, 2017; Noel et al., 2018). Statutory regulations that place strict limitations on the content of alcohol advertising are likely needed to limit the impact of social media alcohol advertising on higher-risk drinkers. Regulations restricting user-generated comments may be needed to further protect low-risk drinkers and those who choose to remain abstinent. In the absence of alcohol marketing regulations, pressure can be applied to social media platforms to introduce new features that would allow users to "opt-in" or "opt-out" of viewing certain content categories. Within the current context, social media users would then have the option to view content published by alcohol brands. 


\section{Limitations}

There are several limitations to the study. Study power may be limited due to the sample size used, and an effect of user engagement values may be seen in larger studies. The results may not be generalizable to other population groups, social media platforms, or product types, and additional research is necessary to verify the reported findings. The study relied on self-report, and due to the anonymous nature of AMT, it is not possible to independently verify participant responses. Additionally, because the desire to drink measurement was a judgement of how others may drink, it may be prone to social desirability bias.

It is not possible to know if the comments were truly written by Facebook users unaffiliated with the included brands or brand representatives posing as Facebook users, although it is unlikely that brand representatives wrote the comments used in the study. The pro-drinking comments may expose the alcohol brands companies to civil or criminal liabilities should an injury occur as a result of a Facebook user reading the comment, and the anti-drinking comments are unlikely to originate from brand representatives by their nature. Furthermore, it is not known whether prodrinking user-generated comments increase the desire to drink, anti-drinking user-generated comments decrease the desire to drink, or both mechanisms are at work because they were compared against each other. Additional research is needed to understand the exact mechanism of action. Finally, order effects may, in part, explain the results because while each group viewed the ads in a different order, participants within the same group viewed the ads in the same order. However, any biases would likely be towards the null due to respondent fatigue. 


\section{Conclusions}

The desire to drink may significantly increase among higher-risk drinkers after exposure to a social media beer advertisement. The desire to drink may also significantly increase among low-risk drinkers or those who are abstinent if the advertisements are paired with pro-drinking user-generated comments. Regulating the content of social media alcohol advertisements may protect higher-risk drinkers, and regulating comments associated with social media alcohol advertisements may offer additional protections for low-risk drinkers and those who are abstinent.

\section{Acknowledgements}

The author acknowledges the contributions of Thomas Babor, David Gregorio, and James Grady who assisted in the design, implementation, and interpretation of the study.

\section{Declaration of Interest}

The author has no conflicts of interest. The study was funded by a fellowship from the Beever Trust Fund. 


\section{References}

Alhabash, S., McAlister, A. R., Quilliam, E. T., Richards, J. I., \& Lou, C. (2015). Alcohol's getting a bit more social: When alcohol marketing messages on Facebook increase young adults' intentions to imbibe. Mass Communication and Society, 18(3), 350-375. doi:

$10.1080 / 15205436.2014 .945651$

Anderson, P., de Bruijn, A., Angus, K., Gordon, R., \& Hastings, G. (2009). Impact of alcohol advertising and media exposure on adolescent alcohol use: a systematic review of longitudinal studies. Alcohol and Alcoholism, 44(3), 229-243.

Babor, T. F., \& Robaina, K. (2016). The Alcohol Use Disorders Identification Test (AUDIT): A review of graded severity algorithms and national adaptations. International Journal of Alcohol and Drug Research, 5(2), 17-24. doi: 10.7895/ijadr.v5i2.222

Barry, A. E., Bates, A. M., Olusanya, O., Vinal, C. E., Martin, E., Peoples, J. E., ... Montano, J. R. (2016). Alcohol marketing on Twitter and Instagram: Evidence of directly advertising to youth/adolescents. Alcohol and Alcoholism, 51(4), 487-492.

Barry, A. E., Johnson, E., Rabre, A., Darville, G., Donovan, K. M., \& Efunbumi, O. (2015). Underage access to online alcohol marketing content: a YouTube case study. Alcohol and Alcoholism, 50(1), 89-94.

Barry, A. E., Padon, A. A., Whiteman, S. D., Hicks, K. K., Carreon, A. K., Crowell, J. R., ... Merianos, A. L. (2018). Alcohol advertising on social media: Examining the content of popular alcohol brands on Instagram. Substance Use \& Misuse, 53(14), 2413-2420. 
Borah, P., \& Xiao, X. (2018). The importance of 'Likes': The interplay of message framing, source, and social endorsement on credibility perceptions of health information on Facebook. Journal of Health Communication, 23(4), 399-411. doi: 10.1080/10810730.2018.1455770

Bordnick, P. S., Traylor, A., Copp, H. L., Graap, K. M., Carter, B., Ferrer, M., \& Walton, A. P. (2008). Assessing reactivity to virtual reality alcohol based cues. Addictive Behaviors, 33(6), 743-756. doi: 10.1016/j.addbeh.2007.12.010

Boyle, S. C., Smith, D. J., Earle, A. M., \& LaBrie, J. W. (2018). What "likes" have got to do with it: Exposure to peers' alcohol-related posts and perceptions of injunctive drinking norms. Journal of American College Health, 66(4), 252-258. doi: 10.1080/07448481.2018.1431895

Bradburn, N., Sudman, S., \& Wansink, B. (2004). Asking questions about attitudes and behavioral intentions. In Asking questions: The definitive guide to questionnaire design - for market research, political polls, and social and health questionnaires, revised edition. San Francisco, CA: John Wiley \& Sons.

Cassisi, J. E., Delehant, M., Tsoutsouris, J. S., \& Levin, J. (1998). Psychophysiological reactivity to alcohol advertising in light and moderate social drinkers. Addictive Behaviors, 23(2), 267-274.

Courtney, A. L., Rapuano, K. M., Sargent, J. D., Heatherton, T. F., \& Kelley, W .M. (2018).

Reward system activation in response to alcohol advertisements predicts college drinking. Journal of Studies on Alcohol and Drugs, 79(1), 29-38. doi: 10.15288/jsad.2018.79.29

Cox, W. M., Yeates, G. N., \& Regan, C. M. (1999). Effects of alcohol cues on cognitive processing in heavy and light drinkers. Drug and Alcohol Dependence, 55(1-2), 85-89. 
de Sousa Fernandes Perna, E. B., Theunissen, E. L., Kuypers, K. P., Evers, E. A., Stiers, P., Toennes, S. W., ... Ramaekers, J. G. (2017). Brain reactivity to alcohol and cannabis marketing during sobriety and intoxication. Addiction Biology, 22(3), 823-832. doi: 10.1111/adb.12351

Eddie, D., Buckman, J. F., Mun, E. Y., Vaschillo, B., Vaschillo, E., Udo, T., ... Bates, M. E. (2013). Different associations of alcohol cue reactivity with negative alcohol expectancies in mandated and inpatient samples of young adults. Addictive Behaviors, 38(4), 2040-2043. doi: 10.1016/j.addbeh.2013.01.006

Erevik, E. K., Pallesen, S., Andreassen, C. S., Vedaa, Ø., \& Torsheim, T. (2018). Who is watching user-generated alcohol posts on social media? Addictive Behaviors, 78, 131-137. doi: 10.1016/j.addbeh.2017.11.023

Erevik, E. K., Torsheim, T., Andreassen, C. S., Vedaa, Ø., \& Pallesen, S. (2017). Disclosure and exposure of alcohol on social media and later alcohol use: A large-scale longitudinal study. Frontiers in Psychology, 8, 1934. doi: 10.3389/fpsyg.2017.01934

France, K. E., Donovan, R. J., Bower, C., Elliott, E. J., Payne, J. M., D'Antoine, H., \& Bartu, A. E. (2014). Messages that increase women's intentions to abstain from alcohol during pregnancy: results from quantitative testing of advertising concepts. BMC Public Health, 14, 30. doi: $10.1186 / 1471-2458-14-30$

Gupta, H., Lam, T., Pettigrew, S., \& Tait, R. J. (2018). Alcohol marketing on YouTube: exploratory analysis of content adaptation to enhance user engagement in different national contexts. BMC Public Health, 18(1), 141.

Hoffman, E. W., Pinkleton, B. E., Weintraub Austin, E., \& Reyes-Velázquez, W. (2014). Exploring college students' use of general and alcohol-related social media and their associations 
with alcohol-related behaviors. Journal of American College Health, 62(5), 328-335. doi: $10.1080 / 07448481.2014 .902837$

Ingjaldsson, J. T., Thayer, J. F., \& Laberg, J. C. (2003a). Craving for alcohol and pre-attentive processing of alcohol stimuli. International Journal of Psychophysiology, 49(1), 29-39.

Ingjaldsson, J. T., Thayer, J. F., \& Laberg, J. C. (2003b). Preattentive processing of alcohol stimuli. Scandinavian Journal of Psychology, 44(2), 161-165.

International Alliance for Responsible Drinking. (2014). Digital Guiding Principles. Retrieved from http://www.k-message.com/wp-content/uploads/2014/10/Digital-Guiding-PrinciplesDGPs.pdf.

International Alliance for Responsible Drinking (IARD). (2011) Guiding Principles: SelfRegulation of Marketing Communications for Beverage Alcohol. Retrieved from http://www.iard.org/wp-content/uploads/2016/01/Guiding-Principles.pdf.

Jernigan, D., Noel, J., Landon, J., Thornton, N., \& Lobstein, T. (2017). Alcohol marketing and youth alcohol consumption: a systematic review of longitudinal studies published since 2008. Addiction, 112(Suppl 1), 7-20.

Jernigan, D. H., Padon, A., Ross, C., \& Borzekowski, D. (2017). Self-reported youth and adult exposure to alcohol marketing in traditional and digital media: Results of a pilot survey. Alcoholism: Clinical and Experimental Research, 41(3), 618-625. doi: 10.1111/acer.13331

Jernigan, D. H., \& Rushman, A. E. (2014). Measuring youth exposure to alcohol marketing on social networking sites: challenges and prospects. Journal of Public Health Policy, 35, 91-104. 
Jones, S. C., Thom, J. A., Davoren, S., \& Barrie, L. (2014). Internet filters and entry pages do not protect children from online alcohol marketing. Journal of Public Health Policy, 35(1), 75-90.

Lee, E., Namkoong, K., Lee, C. H., An, S. K, \& Lee, B. O. (2006). Differences of Photographs Inducing Craving Between Alcoholics and Non-alcoholics. Yonsei Medical Journal, 47(4), 491497. doi: 10.3349/ymj.2006.47.4.491

Lee, J. S., Namkoong, K., Ku, J., Cho, S., Park, J. Y., Choi, Y. K., ... Jung, Y. C. (2008). Social pressure-induced craving in patients with alcohol dependence: application of virtual reality to coping skill training. Psychiatry Investigation, 5(4), 239-243. doi: 10.4306/pi.2008.5.4.239

Lobstein, T., Landon, J., Thornton, N., \& Jernigan, D. (2017). The commercial use of digital media to market alcohol products: a narrative review. Addiction, 112(Suppl 1), 21-27.

Mason, B., Light, J., Escher, T., \& Drobes, D. (2008). Effect of positive and negative affective stimuli and beverage cues on measures of craving in non treatment-seeking alcoholics. Psychopharmacology, 200(1), 141-150. doi: 10.1007/s00213-008-1192-х

Noel, J. K., \& Babor, T. F. (2017). Predicting regulatory compliance in beer advertising on Facebook. Alcohol and Alcoholism, 52, 730-736. doi: 10.1093/alcalc/agx059

Noel, J. K., \& Babor, T. F. (2018). Alcohol advertising on Facebook and drinking intentions among young adults. Journal of Studies on Alcohol and Drugs, 79(5), 751-760. doi: $10.15288 /$ jsad.2018.79.751

Noel, J. K., Babor, T. F., \& Grady, J. (2018). Advertising content, platform characteristics, and the appeal of beer advertising on social media. Alcohol and Alcoholism, 53(5), 619-625. doi: 10.1093/alcalc/agy020 
Noel, J. K., Babor, T. F., \& Robaina, K. (2017). Industry self-regulation of alcohol marketing: A systematic review of content and exposure research. Addiction, 112(Suppl 1), 28-50. doi:

10.1111/add.13410

Petit, G., Kornreich, C., Dan, B., Verbanck, P., \& Campanella, S. (2014). Electrophysiological correlates of alcohol- and non-alcohol-related stimuli processing in binge drinkers: a follow-up study. Journal of Psychopharmacology, 28(11), 1041-1052. doi: 10.1177/0269881114545663

Petit, G., Kornreich, C., Maurage, P., Noël, X., Letesson, C., Verbanck, P., \& Campanella, S. (2012). Early attentional modulation by alcohol-related cues in young binge drinkers: An eventrelated potentials study. Clinical Neurophysiology, 123(5), 925-936. doi:

10.1016/j.clinph.2011.10.042

Petit, G., Kornreich, C., Verbanck, P., \& Campanella, S. (2013). Gender differences in reactivity to alcohol cues in binge drinkers: A preliminary assessment of event-related potentials. Psychiatry Research, 209(3), 494-503. doi: 10.1016/j.psychres.2013.04.005

Ramirez, J. J., Monti, P. M., \& Colwill, R. M. (2015). Alcohol-cue exposure effects on craving and attentional bias in underage college-student drinkers. Psychology of Addictive Behaviors, 29(2), 317-322. doi: 10.1037/adb0000028

Rauniar, R., Rawski, G., Yang, J., \& Johnson, B. (2014). Technology acceptance model (TAM) and social media usage: An empirical study on Facebook. Journal of Enterprise Information Management, 27(1), 6-30. doi: 10.1108/JEIM-04-2012-0011

Reid, M. S., Flammino, F., Starosta, A., Palamar, J., \& Franck, J. (2006). Physiological and subjective responding to alcohol cue exposure in alcoholics and control subjects: evidence for 
appetitive responding. Journal of Neural Transmission, 113(10), 1519-1535. doi:

$10.1007 / \mathrm{s} 00702-005-0439-5$

Rost, K., Stagel, L., \& Frey, B. S. (2016). Digital social norm enforcement: Online firestorms in social media. PLoS One, 11(6), e0155923. doi: 10.1371/journal.pone.0155923

Saunders, J., Aasland, O., Babor, T., de la Fuente, J., \& Grant, M. (1993). Development of the Alcohol Use Disorders Identification Test (AUDIT): WHO Collaborative Project on Early Detection of Persons with Harmful Alcohol Consumption--II. Addiction, 88, 791-804.

Simons, D. J., \& Chabris, C. F. (2012). Common (mis)beliefs about memory: A replication and comparison of telephone and mechanical turk survey methods. PLoS One, 7(12), e51876. doi: 10.1371/journal.pone.0051876

Storkmark, K. M., Field, N. P., Hugdahl, K., \& Horowitz, M. (1997). Selective processing of visual alcohol cues in abstinent alcoholics: An approach-avoidance conflict? Addictive Behaviors, 22(4), 509-519.

Yang, B., \& Zhao, X. (2018). TV, social media, and college students' binge drinking intentions: Moderated mediation models. Journal of Health Communication, 23(1), 61-71. doi:

$10.1080 / 10810730.2017 .1411995$ 